\title{
Association of Serum Sclerostin with Bone Sclerostin in Chronic Kidney Disease is Lost in Glucocorticoid Treated Patients
}

\author{
Henrik Boltenstål ${ }^{1}$ - Abdul Rashid Qureshi ${ }^{1}$. Geert J. Behets ${ }^{2}$ - Bengt Lindholm ${ }^{1}$ - Peter Stenvinkel ${ }^{1}$. \\ Patrick C. D'Haese ${ }^{2} \cdot$ Mathias Haarhaus ${ }^{1}[1]$
}

Received: 25 August 2018 / Accepted: 27 October 2018 / Published online: 7 November 2018

(c) The Author(s) 2018

\begin{abstract}
The osteocytic protein sclerostin inhibits bone turnover. Serum sclerostin rises early in chronic kidney disease (CKD), but if this reflects osteocyte sclerostin production is unclear, since sclerostin is also expressed in extra-skeletal tissue. Glucocorticoid treatment impacts on serum sclerostin, but the effect on the association between serum and bone sclerostin is unknown. We sought to determine whether serum sclerostin reflects bone sclerostin in different CKD stages and how this association is influenced by glucocorticoid treatment. In a cross-sectional analysis, we investigated serum sclerostin, bone sclerostin by immunohistochemistry, and bone histomorphometry in iliac crest bone biopsies from 43 patients with CKD 3-5D, including 14 dialysis patients and 22 transplanted patients (18 kidney, 4 other). Thirty-one patients were on glucocorticoid treatment at time of biopsy. Patients with low bone turnover (bone formation rate $<97 \mu \mathrm{m}^{2} / \mathrm{mm}^{2} /$ day; $N=13$ ) had higher median serum sclerostin levels ( 224.7 vs. $141.7 \mathrm{pg} / \mathrm{ml} ; P=0.004)$ and higher bone sclerostin, expressed as sclerostin positive osteocytes per bone area ( 12.1 vs. $5.0 \mathrm{Scl}+$ osteocytes/B.Ar; $P=0.008)$, than patients with non-low bone turnover $(N=28)$. In linear regression analyses, correcting for age, gender, dialysis status and PTH, serum sclerostin was only associated with bone sclerostin in patients not treated with glucocorticoids $\left(r^{2}=0.6, P=0.018\right)$. For the first time, we describe that female CKD patients have higher median bone sclerostin than males ( 11.7 vs. $5.7 \mathrm{Scl}+$ osteocytes/B.Ar, $P=0.046)$, despite similar serum sclerostin levels and bone histo-morphometric parameters. We conclude that glucocorticoid treatment appears to disrupt the association of serum sclerostin with bone sclerostin in CKD.
\end{abstract}

Keywords Bone turnover · Chronic kidney disease · Sclerostin · Mineral metabolism · Glucocorticoid treatment · Immunohistochemistry

\section{Introduction}

Patients with chronic kidney disease (CKD) have an increased risk of cardiovascular complications [1], which are associated with vascular calcification and disorders of mineral metabolism, including disturbances of bone turnover,

Electronic supplementary material The online version of this article (https://doi.org/10.1007/s00223-018-0491-4) contains supplementary material, which is available to authorized users.

Mathias Haarhaus

Mathias.loberg-haarhaus@sll.se

1 Division of Renal Medicine and Baxter Novum, Karolinska University Hospital at Huddinge, Karolinska Institutet, 14186 Stockholm, Sweden

2 Laboratory of Pathophysiology, Department of Biomedical Sciences, University of Antwerp, Antwerp, Belgium mineralization, and volume, leading to diminished bone quality [2]. In CKD, overall fracture risk is increased; particularly hip fractures have been associated with increased mortality [3]. The complex interrelationships between disturbed mineral metabolism, bone disorders, and vascular calcification-embodied in the term chronic kidney disease-mineral and bone disorder (CKD-MBD) [4]—are linked to premature ageing and associated with progressive pathological changes across all stages of kidney disease [5]. This implies the importance of an early identification of CKD-MBD during the development of CKD, to be able to tailor individual therapies. The prevalence of low bone turnover is increasing among CKD patients [6]. Although treatments are available for high bone turnover, there is a lack of effective evidence based treatment alternatives for adynamic bone disorders [4]. 
Sclerostin, a soluble protein coded by the SOST gene on chromosome 17q12-q21, reduces bone formation by inhibiting the anabolic canonical Wnt pathway in osteoblasts [7]. In mice, knockout of the SOST gene causes increased bone formation and bone strength [8] and modifies the development of renal osteodystrophy [9], while mutations or deletions in the human SOST gene can cause diseases with abnormally high bone mass, such as sclerosteosis or van Buchem disease [7]. With the progression of renal disease, sclerostin levels in serum increase, reaching levels several times higher than those in the healthy population [10-12], in spite of an increased renal elimination with decreasing glomerular filtration rate (GFR) [12]. After kidney transplantation, serum sclerostin decreases initially, but increases again with time from transplantation [13, 14].

Glucocorticoid treatment is common in patients with CKD, both as a component of treatment strategies for underlying autoimmune diseases and for prevention of rejection after kidney transplantation. Endogenous and exogenous glucocorticoids can impact on circulating sclerostin levels [15-17], however, the influence of glucocorticoids on its expression in bone and the association between sclerostin levels in the circulation and in bone are still unclear. Previous studies have shown direct [18], inverse [19], or absent [20] associations between serum sclerostin and mortality, suggesting the existence of, to this date, unknown confounders. Although serum sclerostin is related to vascular calcification [21], SOST expression in calcified arteries is absent or very low [21], which implies that circulating sclerostin levels probably are not of vascular origin.

It has been suggested that serum sclerostin could be used to predict bone turnover in dialysed (CKD stage 5D) patients [11]. Serum sclerostin was superior to PTH in predicting high bone turnover, but the negative predictive value was greater for PTH [11]. Sclerostin antibody treatment leads to increased bone formation in postmenopausal women with low bone mineral density (BMD) [22]. In an animal model of low bone turnover, sclerostin antibody treatment caused improvement of trabecular volume and mineralization, suggesting that inhibition of sclerostin may benefit patients with adynamic bone disease [23]. However, further elucidation of the role of sclerostin in CKD-MBD is needed in order to create solid ground for future treatment strategies [2]. The aim of this study was to investigate whether serum sclerostin levels reflect bone sclerostin and to what extent glucocorticoid treatment has an impact on the association of serum sclerostin levels with bone sclerostin in different stages of CKD, including transplanted patients.

\section{Patients}

Forty-three consecutive patients with CKD stage 3-5, including CKD stage 5D and patients with a kidney transplant, were included after giving written informed consent. All patients had been referred for bone biopsy for histomorphometric analysis at the Department of Nephrology, Karolinska University Hospital, between October 2012 and June 2015. Biopsies were obtained on clinical indication to guide treatment decisions. Reasons for performing bone biopsies were low BMD and increased fracture risk, persistent hypercalcemia or hyperparathyroidism after kidney transplantation, or suspicion of either severely reduced bone turnover or severe hyperparathyroidism. Informed consent was obtained from all individuals included in the study. The clinical and research activities being reported are consistent with the Principles of the Declaration of Istanbul as outlined in the 'Declaration of Istanbul on Organ Trafficking and Transplant Tourism'.

\section{Materials and Methods}

\section{Biochemical Analyses}

Circulating total calcium, phosphate, total alkaline phosphatase (ALP), PTH, C-reactive protein (CRP) and albumin were analysed by routine laboratory methods. In all but two cases, a blood sample was taken at the same time as the bone biopsy. In cases where biochemical data were not available at the time of biopsy, data from the temporally closest samples within 3 months before or after the biopsy were included, whilst data outside this period were considered missing. Estimated GFR (eGFR) was calculated in patients not on dialysis $(N=29)$, using the CKD-EPI creatinine equation [24]. Females were classified as postmenopausal when above the age of 49. Analysis of serum sclerostin was performed using an enzyme-linked immunosorbent assay (ELISA) kit from R\&D systems (Abingdon, UK). Optical density was determined at a wavelength of $450 \mathrm{~nm}$.

\section{Histomorphometric Bone Analyses}

Vertical bone biopsies were retrieved from the anterior iliac crest, using an 8-gauge bone biopsy needle, 3-14 days after double tetracycline labelling with 2 episodes of $250 \mathrm{mg}$ tetracycline twice daily for 2 consecutive days, separated by 10 drug free days. The biopsy material was kept in $70 \%$ ethanol during transportation to the laboratory. Biopsies were dehydrated using increasing concentrations of ethanol, followed by ethyl acetate. After dehydration, the biopsies 
were embedded in methylmethacrylate under $\mathrm{N}_{2}$ atmosphere. Undecalcified $5 \mu \mathrm{m}$ thick sections were stained by the method of Goldner for quantitative histology to determine static bone parameters. Ten- $\mu \mathrm{m}$ thick sections were mounted unstained in $100 \%$ glycerol for fluorescence microscopy and visualization of tetracycline labels. Bone analysis was performed in the Laboratory of Pathophysiology of the University of Antwerp, Belgium, using the semi-automatic AxioVision system (Release 4.5, Carl Zeiss, Oberkochen, Germany). Key parameters that were assessed included bone formation rate (BFR), adjusted apposition rate (AjAR), mineralization lag time, mineral apposition rate, bone area (B.Ar), osteoid area, osteoid width (O.Wi), osteoblast perimeter (Ob.Pm), and osteoclast perimeter (Oc.Pm). Due to technical reasons, dynamic histomorphometry could not be determined in two patients.

\section{Immunohistochemistry of Bone Biopsies}

Five- $\mu \mathrm{m}$ sections of the undecalcified, embedded bone were cut and dried overnight at room temperature. Sections were de-acrylated in xylene, 2-methoxyethylacetate, and acetone before gradual rehydration in 100\%, 96\%, and 70\% ethanol. Endogenous peroxidase was blocked with methanol $+3 \%$ $\mathrm{H}_{2} \mathrm{O}_{2}$, followed by washing in distilled water. A $1 \%$ acetic acid bath was followed by a washing procedure in phosphate buffer solution, followed by blocking with avidin, biotin and normal goat serum (same species as secondary antibody) in phosphate buffer solution for $20 \mathrm{~min}$ each. Sections were then incubated overnight with polyclonal rabbit anti-sclerostin antibody sc-130258 (Santa Cruz Biotechnology, Inc., Dallas, TX, USA) diluted 1/50 in phosphate buffer. The final steps were incubation with biotinylated secondary antibody, followed by incubation with avidin/biotin (Vector Laboratories, Burlingame, CA, USA) and staining with 3-amino9-ethylcarbazole. A short wash in phosphate buffer solution was performed in between the last three steps. Sclerostin immunoreactivity was quantified by counting osteocytes with positive immunostaining in 15 consecutive fields of trabecular bone at a magnification of $\times 200$ (Fig. 1). Results were expressed as $\mathrm{Scl}+$ osteocytes/B.Ar.

\section{Statistical Analyses}

Data were expressed as median (10th-90th percentile), percentage, or relative risk ratio [95\% confidence intervals (CIs)], as appropriate. Statistical significance was set at the level of $P<0.05$, all tests were two-tailed. Comparisons between two groups were assessed with a nonparametric Mann-Whitney test for continuous variables and Fischer's exact test for nominal variables. Associations between continuous variables were determined by Spearman's rank-order correlations. To study the associations of

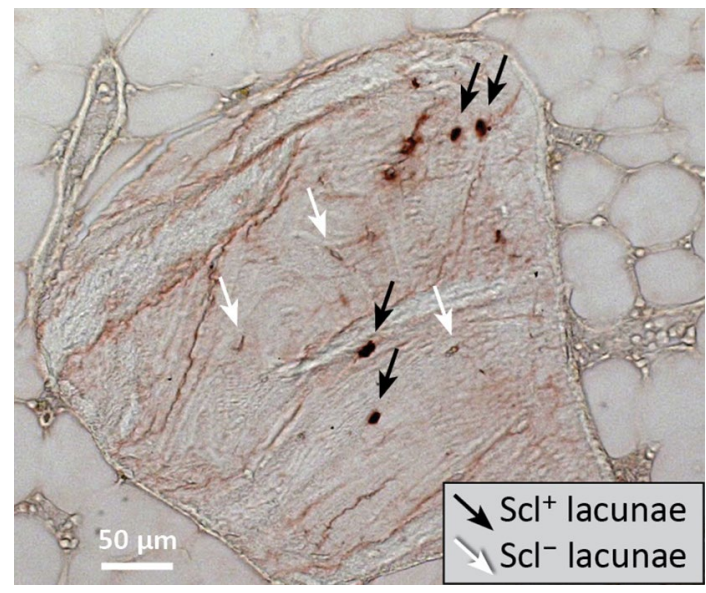

Fig. 1 Immunostaining for sclerostin in trabecular bone. A histological section of trabecular bone with osteocytes with positive (black arrows) and negative (white arrows) immunostaining for sclerostin. Original magnification $\times 200$

circulating biomarkers with low bone turnover (defined as $\mathrm{BFR}<97 \mu \mathrm{m}^{2} / \mathrm{mm}^{2} /$ day), multivariate general linear regression analyses (GENMOD) were performed. The best possible cut-off value for each biomarker was determined by plotting separate receiver operating characteristics (ROC) curves for each biomarker and calculating areas under the curves prior to each dichotomous analysis. Linear regression models for the prediction of serum sclerostin were calculated with gender, dialysis status, 1-SD of sclerostin/B.Ar, 1-SD of age and 1-SD of PTH as independent variables. Statistical analyses were performed using statistical software SAS version 9.4 (SAS, Cary, NC, USA).

\section{Results}

\section{Baseline Characteristics of the Study Population}

The median age of this Caucasian population was 66 (45-78) years, there were 18 females, whereof $16(88 \%)$ were classified as postmenopausal. Fourteen patients (33\%) were on dialysis, while 22 patients $(51 \%)$ had undergone solid-organ transplantation before bone biopsy (1 liver, 3 lung, and 18 kidney transplantations); 15 of these had still a functioning transplanted kidney. Median time from transplantation was $72(12-156)$ months. No patient was transplanted $<6$ months before inclusion. Thirty-one patients (72\%) were treated with glucocorticoids at the time of bone biopsy, 21 of these in combination with other immunosuppressive treatments. In total, 32 patients $(76 \%)$ received immunosuppressive treatment. Non-glucocorticoid immunosuppression consisted of calcineurin inhibitors $(N=20)$, mycophenolate mofetil $(N=14)$, azathioprine $(N=3)$, and 
other immunosuppressive drugs $(N=2)$. Primary causes of renal disease were glomerular disease $(N=15$, of these 14 chronic glomerulonephritis and 1 focal segmental glomerulosclerosis), tubule-interstitial disease $(N=9)$, systemic diseases affecting the kidney $(N=13$, of these 8 diabetes mellitus and 5 hypertension), familial/hereditary nephropathies $(N=5)$ and miscellaneous renal disorders $(N=1)$ according to the ERA-EDTA registry classifications. Medical history, demographic data, results from serum biochemical analyses, histo-morphometric, and immunohistochemical (IHC) analyses of bone biopsies are summarized in Table 1. eGFR was not determined in dialysed patients.

\section{Serum Sclerostin, Bone Sclerostin, and Bone Histo-morphometric Parameters in all Patients}

Serum sclerostin was positively correlated with age $(\rho=0.373, P=0.01)$ and negatively correlated with BFR $(\rho=-0.438, P=0.004)$, B.Ar $(\rho=-0.321, P=0.03)$,
O.Wi $(\rho=-0.341, P=0.02), \operatorname{AjAR}(\rho=-0.313$, $P=0.04)$ and plasma albumin $(\rho=-0.318, P=0.03)$. When analysing the whole cohort, the correlation of serum sclerostin with bone sclerostin, expressed as sclerostin positive osteocytes per B.Ar ( $\mathrm{Scl}+$ osteocytes/B. Ar), did not reach significance $(\rho=0.265, P=0.09)$. Bone sclerostin correlated positively with serum phosphate $(\rho=0.333, P=0.02)$ and negatively with BFR $(\rho=-0.344, P=0.02), \operatorname{AjAR}(\rho=-0.343, P=0.02)$ and B.Ar $(\rho=-0.326, P=0.03)$.

Median serum sclerostin level and Scl+ osteocytes/B. Ar differed significantly between groups with low $(N=13)$ and non-low bone turnover $(N=28)$, the highest values were present in patients with low bone turnover (Fig. 2). When dividing patients into groups of high versus nonhigh bone turnover, no significant differences were found. We found in a GENMOD multivariate regression analysis that high serum sclerostin and low serum PTH were independent predictors of low bone turnover (Table 2).

Table 1 Patient clinical characteristics, biochemical and bone histo-morphometric parameters

\begin{tabular}{|c|c|c|c|c|}
\hline Clinical parameters, $N(\%)$ & All patients $(N=43)$ & No glucocorticoids $(N=12)$ & Glucocorticoids $(N=31)$ & Sig. \\
\hline Females & $18(42)$ & $7(58)$ & $11(36)$ & 0.3 \\
\hline Dialysis & $14(33)$ & $5(47)$ & $9(29)$ & 0.48 \\
\hline Diabetes mellitus & $11(26)$ & $4(33)$ & $7(23)$ & 0.47 \\
\hline Solid-organ transplantation & $22(51)$ & $1(8)$ & $21(68)$ & 0.001 \\
\hline Other immunosuppression & $22(74)(N=41)$ & $1(9)(N=11)$ & $21(100)(N=30)$ & 0.001 \\
\hline Age (years) & $66(45-78)$ & $67(31-80)$ & $64(45-71)$ & 0.059 \\
\hline \multicolumn{5}{|l|}{ Biochemical parameters } \\
\hline eGFR $\left(\mathrm{ml} / \mathrm{min} / 1.73 \mathrm{~m}^{2}\right)$ & $32(12-58)(N=29)$ & $19(6-27)(N=7)$ & $35(16-78)(N=22)$ & 0.002 \\
\hline Phosphate (mmol/l) & $1.1(0.6-1.9)$ & $1.6(0.9-2.0)$ & $1.0(0.5-1.8)$ & 0.046 \\
\hline Calcium (mmol/l) & $2.36(2.18-2.62)$ & $2.27(1.92-2.56)$ & $2.43(2.2-2.63)$ & 0.17 \\
\hline PTH (pmol/l) & $18.0(9.5-90.6)$ & $42(16.3-265.3)$ & $16(8.6-56.4)$ & 0.001 \\
\hline $\operatorname{ALP}(\mu \mathrm{kat} / \mathrm{l})$ & $1.5(0.9-3.9)$ & $1.9(0.9-12.1)$ & $1.4(0.9-3.7)$ & 0.17 \\
\hline $\mathrm{CRP}(\mathrm{mg} / \mathrm{l})$ & $2.3(0.35-32)$ & $1.8(0.3-13.3)$ & $3.8(0.4-33.3)$ & 0.18 \\
\hline Albumin $(g / l)$ & $34(26-39)$ & $34(24-37)$ & $34(26-40)$ & 0.37 \\
\hline Sclerostin (pg/ml) & $165.6(93.2-266.7)$ & $172.2(89.9-366.5)$ & $165.6(94.5-235.1)$ & 0.82 \\
\hline \multicolumn{5}{|l|}{ Bone parameters } \\
\hline $\mathrm{Scl}+$ osteocytes/B.Ar (number/mm²) & $7.4(1.5-36)$ & $6.6(0.6-50.3)$ & $7.8(1.4-31)$ & 0.78 \\
\hline B.Ar ( $\%$ of tissue area) & $16(8-31)$ & $17(7-63)$ & $16(8-27)$ & 0.19 \\
\hline O.Wi $(\mu \mathrm{m})$ & $8.7(4.9-14.9)$ & $10.4(5.3-15.8)$ & $8.6(4.8-12.7)$ & 0.059 \\
\hline Dynamic histomorphometry & $N=41$ & $N=12$ & $N=29$ & \\
\hline $\operatorname{MAR}(\mu \mathrm{m} /$ day $)$ & $0.9(0.1-1.3)$ & $1.03(0.6-1.79)$ & $0.82(0.1-1.24)$ & $\mathbf{0 . 0 2 7}$ \\
\hline $\operatorname{BFR}\left(\mu \mathrm{m}^{2} / \mathrm{mm}^{2} /\right.$ day $)$ & $151(0-1106.3)$ & $413.2(52.3-1524.3)$ & $142.2(0-569.5)$ & 0.029 \\
\hline Mlt (days) & $23.8(6.5-172,342.6)$ & $22.8(9.51-51.5)$ & $27.6(6.2-197,167.0)$ & 0.34 \\
\hline
\end{tabular}

Immunosuppressive treatment refers to one or more of following drug categories at the time of biopsy: glucocorticoids, calcineurin inhibitors, azathioprine, mycophenolate mofetil, or other immunosuppressants. All data is expressed as median (10th-90th percentile unless otherwise stated. Significant differences $(P<0.05)$ indicated in bold

$e G F R$ estimated glomerular filtration rate, $P T H$ intact parathyroid hormone, $A L P$ alkaline phosphatase, $C R P$ C-reactive protein, $S c l+$ immunoreactive for sclerostin, $B . A r$ bone area, $O$.Wi osteoid width, $M A R$ mineral apposition rate, $B F R$ bone formation rate, Mlt mineralization lag time 

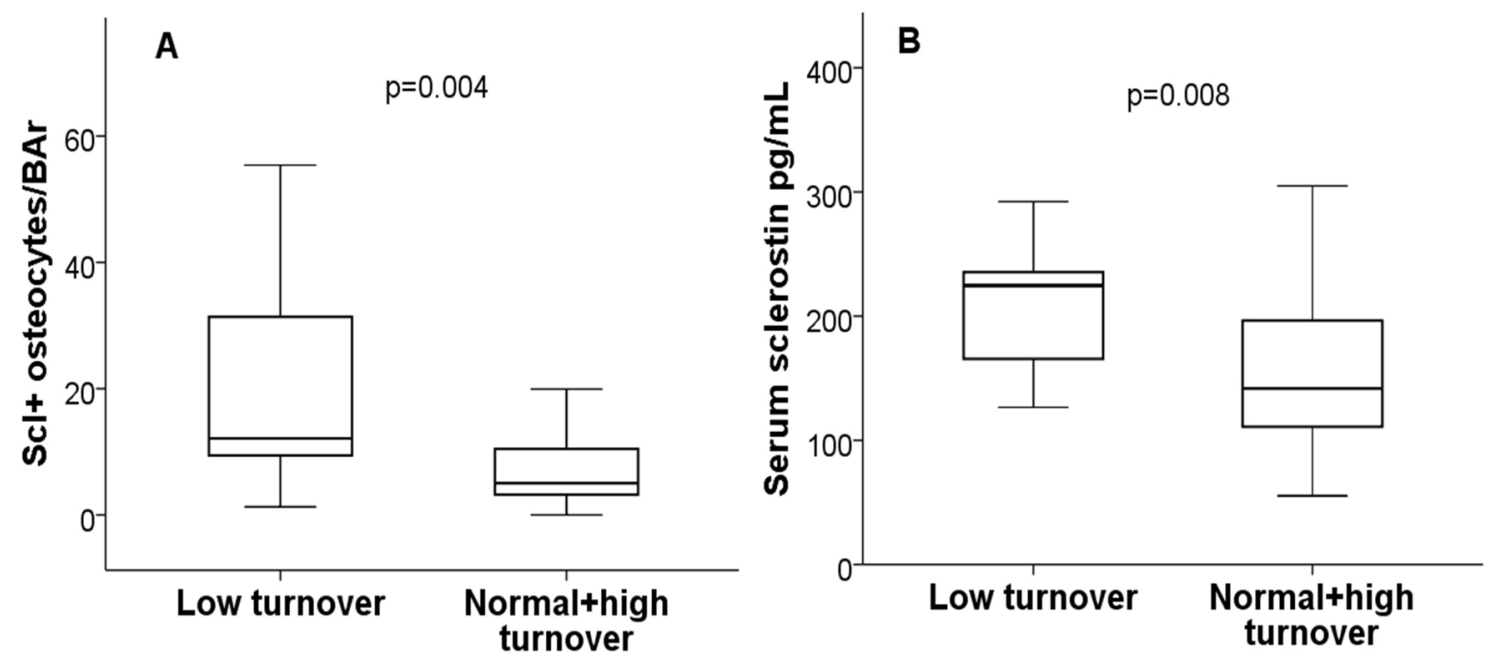

Fig. 2 Differences in serum and bone sclerostin between low $(N=13)$ and normal +high $(N=28)$ bone turnover. Scl+osteocytes/B.Ar number of osteocytes expressing sclerostin per bone area

Table 2 Circulating predictors of low bone turnover by GENMOD analysis in 43 patients

\begin{tabular}{lll}
\hline Variables & Relative ratio (95\% CI) & $P$-values \\
\hline $\begin{array}{l}\text { Sclerostin (above vs. below } \\
180 \mathrm{pg} / \mathrm{ml})\end{array}$ & $1.34(1.04-1.73)$ & 0.02 \\
PTH (above vs. below $17 \mathrm{pmol} / \mathrm{l})$ & $0.75(0.58-0.97)$ & 0.03 \\
ALP (above vs. below $1.5 \mu \mathrm{kat} / \mathrm{l})$ & $0.91(0.69-1.18)$ & 0.48
\end{tabular}

Results are presented as relative ratios with $95 \%$ confidence interval (CI). Cut-off thresholds were chosen based on ROC curve analyses

Sclerostin serum sclerostin, $P T H$ intact parathyroid hormone, ALP alkaline phosphatase

\section{Serum Sclerostin, Bone Sclerostin, and Bone Histo-morphometric Parameters in Patients with Versus Without Glucocorticoid Treatment}

When analysing glucocorticoid-treated patients and nonglucocorticoid treated patients separately, only the latter group exhibited a significant correlation $(\rho=0.608$, $P=0.03$ ) between serum sclerostin and Scl+ osteocytes/B. Ar (Fig. 3). Among non-glucocorticoid treated patients, serum sclerostin further correlated negatively with BFR $(\rho=-0.613, P=0.02)$, O.Wi $(\rho=-0.714, P=0.004)$, and eGFR ( $\rho=-0.829, P=0.02$ ), while correlating positively with age $(\rho=0.587, P=0.02)$. Scl+ osteocytes/B.Ar was also inversely correlated with BFR $(\rho=-0.538, P=0.04)$, B.Ar $(\rho=-0.543, P=0.04)$, and O.Wi $(\rho=-0.560$, $P=0.03)$ in non-glucocorticoid treated patients. When studying glucocorticoid-treated patients, only BFR remained significantly correlated to serum sclerostin $(\rho=-0.481$, $P=0.01$ ). Serum and bone sclerostin levels were similar in patients with or without glucocorticoid treatment. However,
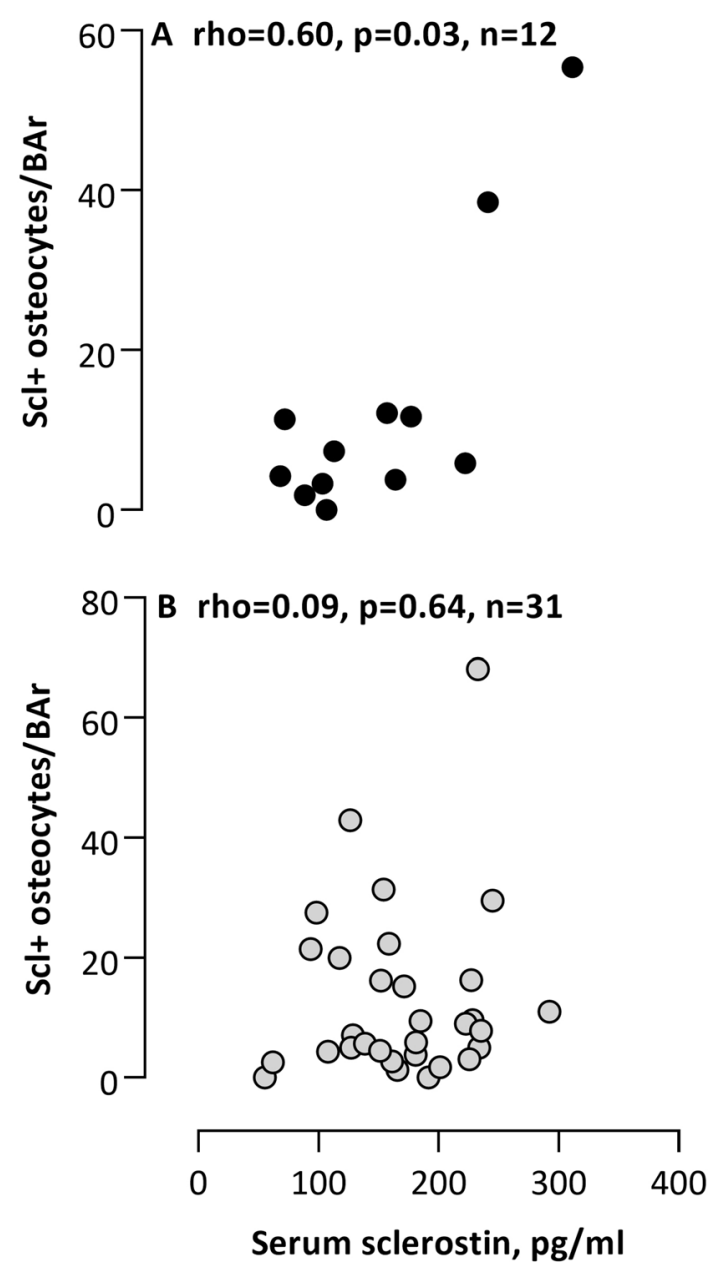

Fig. 3 Associations of serum and bone sclerostin in patients with $(N=31)$ or without glucocorticoid treatment at time of biopsy $(N=12)$. Scl+osteocytes/B.Ar number of osteocytes expressing sclerostin per bone area 
non-glucocorticoid treated patients had higher bone turnover, indicated by higher iPTH, ALP, MAR, AjAR, BFR, and O.Wi levels, and lower kidney function, indicated by higher creatinine and lower eGFR (Table 1). We did not find any significant differences in the association of serum sclerostin with $\mathrm{Scl}+$ osteocytes/B.Ar in patients with or without any other immunosuppressive treatment. In patients not on glucocorticoid treatment, serum sclerostin was predicted by 1-SD of Scl+ osteocytes/B.Ar $(P=0.01)$ when controlling for gender, dialysis status, 1-SD of age and 1-SD of PTH in multiple linear regression analysis (adjusted $r^{2}=0.6$ ). There was no significant association between serum sclerostin and $\mathrm{Scl}+$ osteocytes/B.Ar in glucocorticoid-treated patients in multiple linear regression analyses. These findings remained unchanged after exclusion of PTH from the multivariate analyses, suggesting that PTH was not a confounder, in spite of differences in serum PTH levels between groups. Twenty-one of the glucocorticoid-treated patients had performed solid-organ transplantation before bone biopsy, one transplanted patient was not on glucocorticoid treatment. Corresponding multiple regression analyses based on transplant status rendered similar results (Supplementary Table 1). After excluding patients who had previously received a solid-organ transplant, we still found a difference in the association of serum sclerostin with Scl+ osteocytes/B.Ar between non-glucocorticoid treated patients $(\rho=0.618, P=0.04, N=11)$ and glucocorticoid-treated patients $(\rho=-0.042, P=0.9, N=10)$. Kidney function was comparable in both groups (median eGFR 15.5 and $17 \mathrm{ml} /$ $\mathrm{min} / 1.73 \mathrm{~m}^{2}$ and proportion of dialysis patients 45 and $50 \%$, respectively).

\section{Serum and Bone Sclerostin and Gender}

Females had significantly higher $\mathrm{Scl}+$ osteocytes/B.Ar compared to males, no gender difference was found for serum sclerostin (Supplementary Table 2). Females had lower CRP than males. No other gender differences were found for demographic, serum, or histo-morphometric parameters.

\section{Discussion}

Serum sclerostin concentration and bone sclerostin were associated in CKD patients not on glucocorticoid treatment; supporting the concept that serum sclerostin reflects bone sclerostin. However, for the first time in CKD patients, we report that glucocorticoid treatment appears to disconnect the relationship between bone sclerostin and circulating sclerostin levels. Little is known about the effect of glucocorticoids on this relationship. de Castro et al. [25] demonstrated a suppressive effect of glucocorticoids on both bone sclerostin expression and osteoblastic activity, however, the effect on serum sclerostin is controversial. Glucocorticoid treatment suppresses serum sclerostin acutely [15], but prolonged treatment has been associated with increased circulating sclerostin levels [16]. In contrast, endogenous hypercortisolism is associated with decreased serum sclerostin [17]. While mechanisms accounting for these divergent findings are still unclear, our finding of a dissociation of bone and serum sclerostin in glucocorticoid-treated patients indicate a possible contribution of non-skeletal sources to circulating sclerostin levels. In this respect, the recent suggestion of a rapidly mobilizable vascular storage of sclerostin might contribute to a possible explanation [26]. However, the existence of this vascular storage and a possible effect of glucocorticoids on its mobilization have yet to be confirmed. Furthermore, differences in serum levels detected by different ELISAs [27] and variable associations with kidney function [28] suggest the existence of circulating sclerostin fragments with variable renal clearance, which also could contribute to the observed difference in the association of bone sclerostin with circulating sclerostin levels between glucocorticoidtreated and non-glucocorticoid treated patients, as the former had better preserved kidney function. However, the difference in the association of bone sclerostin with circulating sclerostin levels in glucocorticoid versus non-glucocorticoid treated patients persisted after excluding patients with a solid-organ transplant, in spite of comparable kidney function between groups. We could not identify any previous studies investigating the effect of other immunosuppressive agents on bone sclerostin expression. However, a negative effect of calcineurin inhibitors on BMD has been described [29]. Everolimus, on the other hand, seems to exert a positive effect on bone [30].

Our findings of a disconnection of the association of serum sclerostin with bone sclerostin in glucocorticoidtreated patients could be reproduced in patients who previously had received a solid-organ transplant. A previous study by Pereira et al. [31] described differences in bone sclerostin in children after kidney transplantation, compared to children with pre-dialysis CKD. In contrast to our findings they described higher bone sclerostin in transplanted patients. However, pre-dialysis CKD patients in that study had lower bone sclerostin than healthy controls, which contradicts an earlier description of higher bone sclerostin in adults with pre-dialysis CKD compared to both healthy controls and hemodialysis patients [32]. It has previously been reported that serum sclerostin levels decrease shortly after kidney transplantation, possibly related to improved renal clearance, increased physical activity, and an early inhibitory effect of glucocorticoid treatment on osteocytes, but increase again with time from transplantation [13, 14]. On the other hand, no significant differences in serum sclerostin before and after kidney transplantation were found in postmenopausal women [33]. 
Silencing of the SOST gene or treatment with a sclerostin antibody in mice has rendered conflicting results concerning the association of serum sclerostin with bone turnover [34-36]. Possible explanations are differences in experimental methods, sclerostin assays, type of bone, and species specific differences in regulation of bone turnover. Our observation of an inverse correlation of serum sclerostin with bone turnover accords with de Oliveira et al. [37] and Cejka et al. [11], who described a negative association between serum sclerostin and bone turnover parameters in peritoneal dialysis and hemodialysis patients, respectively. Cejka et al. [11] suggested that sclerostin was superior to $\mathrm{PTH}$ in predicting high turnover in CKD stage 5D. In contrast, the current findings suggest that serum sclerostin may be a marker for low rather than high bone turnover, with good sensitivity, but low specificity, which, together with the observed inverse correlations of serum and bone sclerostin with BFR, supports the concept of sclerostin as a marker of low bone turnover. This would also be in accordance with its physiological role as inhibitor of Wnt signalling induced bone formation [7]. We found no correlation between serum sclerostin and serum PTH. Previous reports on the association of circulating sclerostin with PTH in CKD have been inconsistent, ranging from negative [11] to absent associations [10, 18, 37]. Differences in sclerostin assays have been suggested as a possible explanation for these divergent findings [27, 28], and, in addition, the current study may lack power to detect an association of circulating sclerostin with circulating PTH.

For the first time, we report on a difference in bone sclerostin between male and female CKD patients. Our finding of a lower bone sclerostin in males compared to females is in accordance with a recent report on an inhibitory effect of androgens on human osteocytic sclerostin expression in vitro [38]. In the same study, serum sclerostin correlated negatively with serum testosterone in healthy and hypogonadal men, independently of several confounders, among them PTH, 25OH vitamin D, and age. However, data on sex differences in serum sclerostin are conflicting. While several studies report that serum sclerostin levels are higher among males than females, both during childhood and puberty [39, 40] and in adults [10,41], Amrein et al. [42] did not find any sex differences in adults after adjustment for confounders. Our finding of no sex difference of serum sclerostin levels accords with the findings reported by Malluche et al. [43] in dialysis patients. These discrepancies between different studies might be due to differences in sclerostin assays used, differences in total bone mass, extra-skeletal sources of circulating sclerostin or other yet unknown confounders. In the current study, besides bone sclerostin, only CRP differed significantly between men and women. The effect of inflammation on bone sclerostin expression in CKD has, to our knowledge, not yet been studied. However, in ankylosing spondylitis, lower circulating sclerostin levels are associated with higher CRP [44].

A number of strengths and limitations of the present study needs consideration. The inclusion of patients in different CKD stages, including transplanted patients, strengthens the external validity of the results. Moreover, the combination of histo-morphometric analysis of bone biopsies with determination of sclerostin in serum and bone is another strength of the study. The relevance of our findings is underlined by the imminent introduction of a novel sclerostin antibody for the treatment of osteoporosis. However, the relatively small number of patients, the predominance of Caucasian ethnicity, and the cross-sectional and observational character are limitations of the study. Although patients were referred for a bone biopsy on clinical indication, the divergence of indications may reduce the risk for selection bias. The observed serum sclerostin levels in the current study differ from those reported by de Oliveira et al. [37] in dialysis patients. This might be due to differences in sclerostin assays used. The anti-sclerostin antibody used in the current study has been used before for bone IHC analysis [45]. A further explanation could be the higher proportion of patients with better preserved kidney function in the current study, since serum sclerostin increases with decreasing GFR [12]. However, the dialysability of sclerostin [46] and differences between different sclerostin assays [27, 28] underline the importance of standardized sampling procedures. Other factors that might affect serum sclerostin levels are underlying causes of CKD [47] and age [41], although the latter might not be an independent confounder [48]. The current study did not include measurement of BMD. Sclerostin antibody therapy in humans has been shown to increase BMD [22] and high sclerostin levels are associated with low BMD [43], which is in line with our finding of relatively weak but significant negative correlations between both serum and bone sclerostin with B.Ar. Impaired mineralization and bone formation have been suggested as possible mechanisms for the association of sclerostin with low BMD, which is in accordance with associations between serum and bone sclerostin, BFR and O.Wi in the current study.

In conclusion, we report that glucocorticoid treatment appears to disconnect the association between serum sclerostin levels and bone sclerostin in CKD patients, which is observed in CKD patients not on glucocorticoid treatment. We also demonstrate that serum and bone sclerostin are inversely associated with bone turnover and bone mass in CKD, that serum sclerostin levels may be a better marker for low than for high bone turnover, and that women with CKD have higher bone sclerostin levels than men, despite serum sclerostin levels being similar. 
Acknowledgements We thank Björn Anderstam and Monica Eriksson for excellent laboratory assistance and Annika Nilsson, Sofia Garpemo, Yvonne Eklöf and Ulrika Jensen for excellent clinical assistance in collection and handling of samples. Baxter Novum is the result of a Grant from Baxter Healthcare to Karolinska Institutet. This study was supported by the Swedish Heart-Lung Foundation and by Stockholm County Council.

\section{Compliance with Ethical Standards}

Conflict of interest Bengt Lindholm is employed and funded by Baxter Healthcare and owns stock in the company. Peter Stenvinkel has received remunerations from Baxter and Pfizer/BMS, funding from Astra Zeneca and Bayer, and has served as Consultant for Corvidia, Abbvie, Baxter, and Reata. Mathias Haarhaus has received remuneration from Genzyme, Amgen, Pfizer, and Fresenius, funding from Capio, and has served as consultant for Genzyme, Resverlogix, and Amgen. None of the other authors declare any conflicts of interest.

Human and Animal Rights and Informed Consent All procedures performed in this study involving human participants were in accordance with the Ethical Standards of the Institutional and/or National Research Committee and with the 1964 Helsinki Declaration and its later amendments.

Open Access This article is distributed under the terms of the Creative Commons Attribution 4.0 International License (http://creativeco mmons.org/licenses/by/4.0/), which permits unrestricted use, distribution, and reproduction in any medium, provided you give appropriate credit to the original author(s) and the source, provide a link to the Creative Commons license, and indicate if changes were made.

\section{References}

1. Schlieper G, Hess K, Floege J, Marx N (2016) The vulnerable patient with chronic kidney disease. Nephrol Dial Transplant 31(3):382-390. https://doi.org/10.1093/ndt/gfv041

2. Brandenburg VM, D'Haese P, Deck A, Mekahli D, Meijers B, Neven E, Evenepoel P (2016) From skeletal to cardiovascular disease in 12 steps-the evolution of sclerostin as a major player in CKD-MBD. Pediatr Nephrol 31(2):195-206. https://doi. org/10.1007/s00467-015-3069-7

3. Coco M, Rush H (2000) Increased incidence of hip fractures in dialysis patients with low serum parathyroid hormone. Am J Kidney Dis 36(6):1115-1121. https://doi.org/10.1053/ ajkd.2000.19812

4. Kidney Disease: Improving Global Outcomes (KDIGO) CKDMBD Work Group (2009) KDIGO clinical practice guideline for the diagnosis, evaluation, prevention, and treatment of chronic kidney disease-mineral and bone disorder (CKD-MBD). Kidney Int 76(Suppl 113):S1-S130. https://doi.org/10.1038/ki.2009.188

5. Stenvinkel P, Larsson TE (2013) Chronic kidney disease: a clinical model of premature aging. Am J Kidney Dis 62(2):339-351. https ://doi.org/10.1053/j.ajkd.2012.11.051

6. Bover J, Urena P, Brandenburg V, Goldsmith D, Ruiz C, DaSilva I, Bosch RJ (2014) Adynamic bone disease: from bone to vessels in chronic kidney disease. Semin Nephrol 34(6):626-640. https ://doi.org/10.1016/j.semnephrol.2014.09.008

7. van Bezooijen RL, Papapoulos SE, Hamdy NA, ten Dijke P, Löwik CW (2005) Control of bone formation by osteocytes? Lessons from the rare skeletal disorders sclerosteosis and van
Buchem disease. BoneKEy-Osteovision 2:33-38. https://doi. org/10.1138/20050189

8. Li X, Ominsky MS, Niu QT, Sun N, Daugherty B, D'Agostin D, Kurahara C, Gao Y, Cao J, Gong J, Asuncion F, Barrero M, Warmington K, Dwyer D, Stolina M, Morony S, Sarosi I, Kostenuik PJ, Lacey DL, Simonet WS, Ke HZ, Paszty C (2008) Targeted deletion of the sclerostin gene in mice results in increased bone formation and bone strength. J Bone Miner Res 23(6):860-869. https://doi.org/10.1359/jbmr.080216

9. Kaesler N, Verhulst A, De Maré A, Deck A, Behets GJ, Hyusein A, Evenepoel P, Floege J, Marx N, Babler A, Kramer I, Kneissel M, Kramann R, Weis D, D'Haese PC, Brandenburg VM (2018) Sclerostin deficiency modifies the development of CKD-MBD in mice. Bone 107:115-123. https://doi.org/10.1016/j. bone.2017.11.015

10. Behets GJ, Viaene L, Meijers B, Blocki F, Brandenburg VM, Verhulst A, D'Haese PC, Evenepoel P (2017) Circulating levels of sclerostin but not DKK1 associate with laboratory parameters of CKD-MBD. PLoS ONE 12(5):e0176411. https://doi.org/10.1371/ journal.pone.0176411 (eCollection 2017)

11. Cejka D, Herberth J, Branscum AJ, Fardo DW, Monier-Faugere MC, Diarra D, Haas M, Malluche HH (2011) Sclerostin and Dickkopf-1 in renal osteodystrophy. Clin J Am Soc Nephrol 6(4):877882. https://doi.org/10.2215/CJN.06550810

12. Cejka D, Marculescu R, Kozakowski N, Plischke M, Reiter T, Gessl A, Haas M (2014) Renal elimination of sclerostin increases with declining kidney function. J Clin Endocrinol Metab 99(1):248-255. https://doi.org/10.1210/jc.2013-2786

13. Bonani M, Rodriguez D, Fehr T, Mohebbi N, Brockmann J, Blum M, Graf N, Frey D, Wuthrich RP (2014) Sclerostin blood levels before and after kidney transplantation. Kidney Blood Press Res 39(4):230-239. https://doi.org/10.1159/000355781

14. Evenepoel P, Claes K, Viaene L, Bammens B, Meijers B, Naesens M, Sprangers B, Kuypers D (2016) Decreased circulating sclerostin levels in renal transplant recipients with persistent hyperparathyroidism. Transplantation 100(10):2188-2193. https://doi. org/10.1097/TP.0000000000001311

15. Brabnikova Maresova K, Pavelka K, Stepan JJ (2013) Acute effects of glucocorticoids on serum markers of osteoclasts, osteoblasts, and osteocytes. Calcif Tissue Int 92(4):354-361. https:// doi.org/10.1007/s00223-012-9684-4

16. Gifre L, Ruiz-Gaspa S, Monegal A, Nomdedeu B, Filella X, Guanabens N, Peris P (2013) Effect of glucocorticoid treatment on Wnt signalling antagonists (sclerostin and Dkk-1) and their relationship with bone turnover. Bone 57(1):272-276. https://doi. org/10.1016/j.bone.2013.08.016

17. van Lierop AH, van der Eerden AW, Hamdy NA, Hermus AR, den Heijer M, Papapoulos SE (2012) Circulating sclerostin levels are decreased in patients with endogenous hypercortisolism and increase after treatment. J Clin Endocrinol Metab 97(10):E1953E1957. https://doi.org/10.1210/jc.2012-2218

18. Goncalves FL, Elias RM, dos Reis LM, Graciolli FG, Zampieri FG, Oliveira RB, Jorgetti V, Moyses RM (2014) Serum sclerostin is an independent predictor of mortality in hemodialysis patients. BMC Nephrol 15:190. https://doi.org/10.1186/1471-2369-15-190

19. Drechsler C, Evenepoel P, Vervloet MG, Wanner C, Ketteler M, Marx N, Floege J, Dekker FW, Brandenburg VM, NECOSAD Study Group (2015) High levels of circulating sclerostin are associated with better cardiovascular survival in incident dialysis patients: results from the NECOSAD study. Nephrol Dial Transplant 30(2):288-293. https://doi.org/10.1093/ndt/gfu301

20. Desjardins L, Liabeuf S, Oliveira RB, Louvet L, Kamel S, Lemke HD, Vanholder R, Choukroun G, Massy ZA, European Uremic Toxin Work Group (2014) Uremic toxicity and sclerostin in chronic kidney disease patients. Nephrol Ther 10(6):463-470. https://doi.org/10.1016/j.nephro.2014.04.002 
21. Qureshi AR, Olauson H, Witasp A, Haarhaus M, Brandenburg V, Wernerson A, Lindholm B, Soderberg M, Wennberg L, Nordfors L, Ripsweden J, Barany P, Stenvinkel P (2015) Increased circulating sclerostin levels in end-stage renal disease predict biopsyverified vascular medial calcification and coronary artery calcification. Kidney Int 88(6):1356-1364. https://doi.org/10.1038/ ki.2015.194

22. McClung MR, Grauer A, Boonen S, Bolognese MA, Brown JP, Diez-Perez A, Langdahl BL, Reginster JY, Zanchetta JR, Wasserman SM, Katz L, Maddox J, Yang YC, Libanati C, Bone HG (2014) Romosozumab in postmenopausal women with low bone mineral density. N Engl J Med 370(5):412-420. https:// doi.org/10.1056/NEJMoa1305224

23. Moe SM, Chen NX, Newman CL, Organ JM, Kneissel M, Kramer I, Gattone VH II, Allen MR (2015) Anti-sclerostin antibody treatment in a rat model of progressive renal osteodystrophy. J Bone Miner Res 30(3):499-509. https://doi.org/10.1002/ jbmr.2372

24. Levey AS, Stevens LA, Schmid CH, Zhang YL, Castro AF III, Feldman HI, Kusek JW, Eggers P, Van Lente F, Greene T, Coresh J, CKD EPI (2009) A new equation to estimate glomerular filtration rate. Ann Intern Med 150(9):604-612

25. de Castro LF, Lozano D, Dapia S, Portal-Nunez S, Caeiro JR, Gomez-Barrena E, Esbrit P (2010) Role of the N- and C-terminal fragments of parathyroid-hormone-related protein as putative therapies to improve bone regeneration under high glucocorticoid treatment. Tissue Eng A 16(4):1157-1168. https://doi. org/10.1089/ten.TEA.2009.0355

26. Borawski J, Zoltko J, Labij-Reduta B, Koc-Zorawska E, Naumnik B (2018) Effects of enoxaparin on intravascular sclerostin release in healthy men. J Cardiovasc Pharmacol Ther. https:// doi.org/10.1177/1074248418770623

27. Piec I, Washbourne C, Tang J, Fisher E, Greeves J, Jackson S, Fraser WD (2016) How accurate is your sclerostin measurement? Comparison between three commercially available sclerostin ELISA kits. Calcif Tissue Int 98(6):546-555. https://doi. org/10.1007/s00223-015-0105-3

28. Delanaye P, Paquot F, Bouquegneau A, Blocki F, Krzesinski JM, Evenepoel P, Pottel H, Cavalier E (2018) Sclerostin and chronic kidney disease: the assay impacts what we (thought to) know. Nephrol Dial Transplant 33(8):1404-1410. https://doi. org/10.1093/ndt/gfx282

29. Marcen R, Caballero C, Pascual J, Teruel JL, Tenorio M, Ocana J, Villafruela JJ, Burgos FJ, Fernandez AM, Muriel A, Ortuno J (2006) Lumbar bone mineral density in renal transplant patients on neoral and tacrolimus: a four-year prospective study. Transplantation 81(6):826-831. https://doi.org/10.1097/01.tp.00002 03557.36884.e3

30. Kneissel M, Luong-Nguyen NH, Baptist M, Cortesi R, Zumstein-Mecker S, Kossida S, O'Reilly T, Lane H, Susa M (2004) Everolimus suppresses cancellous bone loss, bone resorption, and cathepsin K expression by osteoclasts. Bone 35(5):11441156. https://doi.org/10.1016/j.bone.2004.07.013

31. Pereira RC, Valta H, Tumber N, Salusky IB, Jalanko H, Makitie O, Wesseling Perry K (2015) Altered osteocyte-specific protein expression in bone after childhood solid organ transplantation. PLoS ONE 10(9):e0138156. https://doi.org/10.1371/journ al.pone. 0138156

32. Sabbagh Y, Graciolli FG, O'Brien S, Tang W, dos Reis LM, Ryan S, Phillips L, Boulanger J, Song W, Bracken C, Liu S, Ledbetter S, Dechow P, Canziani ME, Carvalho AB, Jorgetti V, Moyses RM, Schiavi SC (2012) Repression of osteocyte Wnt/ beta-catenin signaling is an early event in the progression of renal osteodystrophy. J Bone Miner Res 27(8):1757-1772. https ://doi.org/10.1002/jbmr.1630
33. Tomei P, Zaza G, Granata S, Gatti D, Fraccarollo C, Gesualdo L, Boschiero L, Lupo A (2014) Sclerostin and Dickkopf-1 in post-menopausal renal allograft recipients. Transplant Proc 46(7):2241-2246. https://doi.org/10.1016/j.transproce ed.2014.07.024

34. Cejka D, Parada-Rodriguez D, Pichler S, Marculescu R, Kramer I, Kneissel M, Gross T, Reisinger A, Pahr D, Monier-Faugere MC, Haas M, Malluche HH (2016) Only minor differences in renal osteodystrophy features between wild-type and sclerostin knockout mice with chronic kidney disease. Kidney Int 90(4):828-834. https://doi.org/10.1016/j.kint.2016.06.019

35. Ryan ZC, Ketha H, McNulty MS, McGee-Lawrence M, Craig TA, Grande JP, Westendorf JJ, Singh RJ, Kumar R (2013) Sclerostin alters serum vitamin D metabolite and fibroblast growth factor 23 concentrations and the urinary excretion of calcium. Proc Natl Acad Sci USA 110(15):6199-6204. https:// doi.org/10.1073/pnas.1221255110

36. McDonald MM, Reagan MR, Youlten SE, Mohanty ST, Seckinger A, Terry RL, Pettitt JA, Simic MK, Cheng TL, Morse A, Le LMT, Abi-Hanna D, Kramer I, Falank C, Fairfield H, Ghobrial IM, Baldock PA, Little DG, Kneissel M, Vanderkerken K, Bassett JHD, Williams GR, Oyajobi BO, Hose D, Phan TG, Croucher P (2017) Inhibiting the osteocyte-specific protein sclerostin increases bone mass and fracture resistance in multiple myeloma. Blood 129(26):3452-3464. https://doi.org/10.1182/ blood-2017-03-773341

37. de Oliveira RA, Barreto FC, Mendes M, dos Reis LM, Castro JH, Britto ZM, Marques ID, Carvalho AB, Moyses RM, Jorgetti $\mathrm{V}$ (2015) Peritoneal dialysis per se is a risk factor for sclerostinassociated adynamic bone disease. Kidney Int 87(5):1039-1045. https://doi.org/10.1038/ki.2014.372

38. Di Nisio A, De Toni L, Speltra E, Rocca MS, Taglialavoro G, Ferlin A, Foresta C (2015) Regulation of sclerostin production in human male osteocytes by androgens: experimental and clinical evidence. Endocrinology 156(12):4534-4544. https://doi. org/10.1210/en.2015-1244

39. Tsentidis C, Gourgiotis D, Kossiva L, Marmarinos A, Doulgeraki A, Karavanaki K (2016) Sclerostin distribution in children and adolescents with type 1 diabetes mellitus and correlation with bone metabolism and bone mineral density. Pediatr Diabetes 17(4):289-299. https://doi.org/10.1111/pedi.12288

40. Kirmani S, Amin S, McCready LK, Atkinson EJ, Melton LJ III, Muller R, Khosla S (2012) Sclerostin levels during growth in children. Osteoporos Int 23(3):1123-1130. https://doi. org/10.1007/s00198-011-1669-z

41. Modder UI, Hoey KA, Amin S, McCready LK, Achenbach SJ, Riggs BL, Melton LJ III, Khosla S (2011) Relation of age, gender, and bone mass to circulating sclerostin levels in women and men. J Bone Miner Res 26(2):373-379. https://doi.org/10.1002/ jbmr.217

42. Amrein K, Amrein S, Drexler C, Dimai HP, Dobnig H, Pfeifer K, Tomaschitz A, Pieber TR, Fahrleitner-Pammer A (2012) Sclerostin and its association with physical activity, age, gender, body composition, and bone mineral content in healthy adults. $\mathrm{J}$ Clin Endocrinol Metab 97(1):148-154. https://doi.org/10.1210/ jc.2011-2152

43. Malluche HH, Davenport DL, Cantor T, Monier-Faugere MC (2014) Bone mineral density and serum biochemical predictors of bone loss in patients with CKD on dialysis. Clin J Am Soc Nephrol 9(7):1254-1262. https://doi.org/10.2215/CJN.09470 913

44. Klingberg E, Nurkkala M, Carlsten H, Forsblad-d'Elia H (2014) Biomarkers of bone metabolism in ankylosing spondylitis in relation to osteoproliferation and osteoporosis. J Rheumatol 41(7):1349-1356. https://doi.org/10.3899/jrheum.131199 
45. Delgado-Calle J, Arozamena J, Garcia-Renedo R, GarciaIbarbia C, Pascual-Carra MA, Gonzalez-Macias J, Riancho JA (2011) Osteocyte deficiency in hip fractures. Calcif Tissue Int 89(4):327-334. https://doi.org/10.1007/s00223-011-9522-0

46. Bielesz BO, Hempfing T, Kieweg H, Marculescu R, Haas M, Cejka D (2014) Sclerostin declines during hemodialysis and appears in Dialysate. Blood Purif 38(1):30-36. https://doi. org/10.1159/000364992
47. Jankowska M, Haarhaus M, Qureshi AR, Lindholm B, Evenepoel P, Stenvinkel P (2017) Sclerostin-a debutant on the autosomal dominant polycystic kidney disease scene? Kidney Int Rep 2(3):481-485. https://doi.org/10.1016/j.ekir.2017.01.001

48. Pelletier S, Dubourg L, Carlier MC, Hadj-Aissa A, Fouque D (2013) The relation between renal function and serum sclerostin in adult patients with CKD. Clin J Am Soc Nephrol 8(5):819-823. https://doi.org/10.2215/CJN.07670712 